\title{
Preparing Immunolocalization Slides of Maize Meiotic Chromosomes for Three-dimensional Microscopy
}

Qian Du and Wojciech P. Pawlowski

Section of Plant Biology, School of Integrative Plant Science, Cornell University, Ithaca, NY 14853, USA *For correspondence: wp45@cornell.edu

\begin{abstract}
[Abstract] The protocol provides fully detailed steps for preparing microscopic slides of acrylamideembedded maize meiotic cells. This method is particularly useful for examining chromatin structure and chromosome arrangement without destroying the three-dimensional organization of the nucleus.
\end{abstract}

Keywords: Three-dimensional microscopy, Immunolocalization, Meiocytes, Chromosomes, Maize

[Background] Meiosis is a dynamic process involving homologous chromosomes pairing, synapsis, and recombination. Cytological analysis to investigate localization and dynamics of meiotic proteins are crucial for understanding details of these processes. In many microscopic slide preparation methods, spatial chromatin organization is damaged by either mechanical processing or chemical solvents. Here, we describe a three-dimensional microscopy protocol to analyze chromatin structure and meiotic protein localization without disturbing nuclear organization.

\section{Materials and Reagents}

1. 15-ml Falcon tubes (VWR, catalog number: 62406-200)

2. $1.5-\mathrm{ml}$ microcentrifuge tubes (Fisher Scientific, catalog number: 05-408-129)

3. Small Petri dishes (VWR, catalog number: 25384-302)

4. Microscopic glass slides (Thermo Fisher Scientific, catalog number: 12-550D)

5. Scalpels (Fine Science Tools, catalog numbers: 10003-12 and 10010-00)

6. Parafilm (Bemis, catalog number: PM-999)

7. Glass microscope coverslip (VWR, catalog number: 48366-067)

8. Six-well tissue culture plate (Becton Dickinson, catalog number: 35-1146)

9. Tupperware box

10. Diamond marker pen (VWR, catalog number: 103302-470)

11. Nail polish

12. BSA (bovine serum albumin, Sigma, catalog number: A9418)

13. $16 \%$ paraformaldehyde (Electron Microscopy Sciences, catalog number: 15710)

14. Acrylamide/bisacrylamide solution $(30 \%$ acrylamide $+0.8 \%$ bisacrylamide; Roche, catalog number: 11-685-821-001)

15. PIPES (Sigma-Aldrich, catalog number: P6757)

16. $\mathrm{KCl}$ (Sigma-Aldrich, catalog number: P3911) 
17. $\mathrm{NaCl}$ (Sigma-Aldrich, catalog number: $\mathrm{S} 7653)$

18. EDTA (Fisher, catalog number: AC118430010)

19. EGTA (OmniPur, catalog number: $4100-50 G$ )

20. $\mathrm{Na}_{2} \mathrm{HPO}_{4}$ (Fisher, catalog number: BP332-500)

21. $\mathrm{KH}_{2} \mathrm{PO}_{4}$ (Fisher, catalog number: $\mathrm{P} 380-500$ )

22. Triton $\mathrm{X}-100$ (Sigma-Aldrich, catalog number: T8787)

23. Tween 20 (Fisher, catalog number: BP337-100)

24. DABCO (1,4 diazabicyclo-[2,2,2] octane, Sigma, catalog number: D-2522)

25. Tris (Fisher, catalog number: BP152-500)

26. Glycerol (Fisher, catalog number: BP229-1)

27. DAPI solution (4,6-diamidino-2-phenylindole; Vector Laboratories, catalog number: $\mathrm{H}-1200$ )

28. Spermine tetra $\mathrm{HCl}$ (Sigma, catalog number: S-2876)

29. Spermidine (Calbiochem, catalog number: 56766 )

30. DTT (Calbiochem, catalog number: 233155)

31. Sorbitol (Sigma, catalog number: S1876)

32. Ammonium persulfate (Acros, catalog number: 327081000)

33. Sodium sulfite (Fisher, catalog number: S447-500)

34. 1x Bufffer A (see Recipes)

35. 2x Buffer A (see Recipes)

36. 10x Buffer A salts (see Recipes)

37. Spermine stock (see Recipes)

38. Spermidine stock (see Recipes)

39. DTT stock (see Recipes)

40. Sorbitol solution (see Recipes)

41. $20 \%(w / v)$ Sodium sulfite (see Recipes)

42. $20 \%(\mathrm{w} / \mathrm{v})$ Ammonium persulfate (see Recipes)

43. $10 x$ PBS (see Recipes)

44. Permeabilization buffer (see Recipes)

45. Blocking buffer (see Recipes)

46. Washing buffer (see Recipes)

47. DABCO antifade solution (see Recipes)

48. DAPI solution (see Recipes)

49. Carnoy's fixative (see Recipes)

\section{Equipment}

1. Fine-tip forceps (Fine Science Tools, catalog number: 11252-30)

2. $-20{ }^{\circ} \mathrm{C}$ freezer

3. Dissecting microscope 
4. Fluorescence microscope

5. Rocking platform shaker

\section{Procedure}

A. Maize anther fixation

1. Harvest immature inflorescences and keep them wrapped in wet paper towels. Analyze anthers from several buds to determine the meiosis stage.

Note: Maize meiocytes development within a tassel is well synchronized; meiosis starts in the middle of the tassel and extends bi-directionally. Maize tassels from 45 to 55-day-old plants can be dissected to determine the meiosis stage. Collect flower buds from several positions along the tassel as shown in Figure 1. Fix the buds in Carnoy's fixative for 15 min. Dissect anthers and release meiocytes by breaking up the anther with a scalpel and forceps. Stain with DAPI and check meiosis progression under a fluorescence microscope following Dukowic-Schulze et al. (2014).

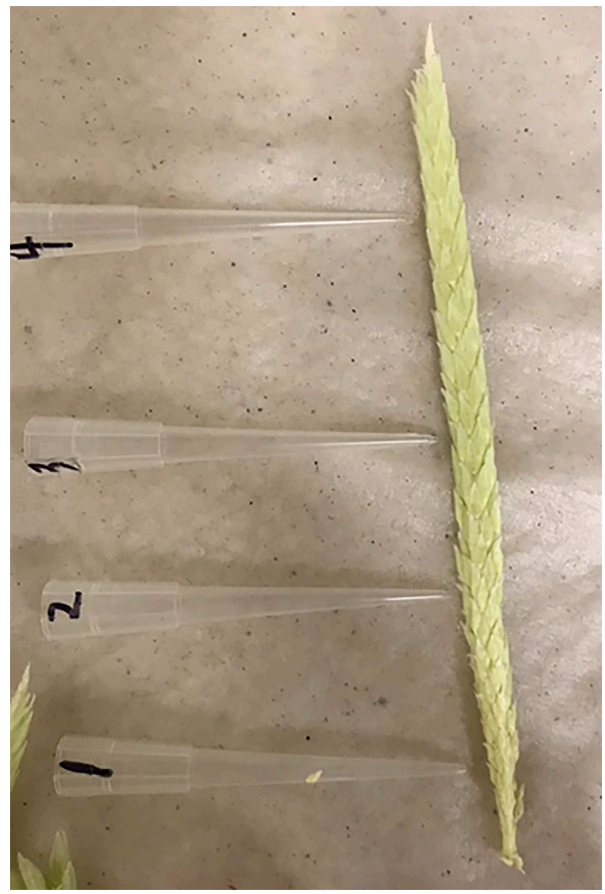

Figure 1. Tassel from a 52-day-old maize plant

2. Dissect anthers from buds at appropriate stages and place them in $2 \mathrm{ml}$ of $1 \times$ Buffer $A$ in the small Petri dish. Then, add $1 \mathrm{ml} 2 x$ Buffer $A$ and $1 \mathrm{ml} 16 \%$ formaldehyde (Video 1, Figure 2). Note: After staging, anthers should be fixed as soon as possible. 


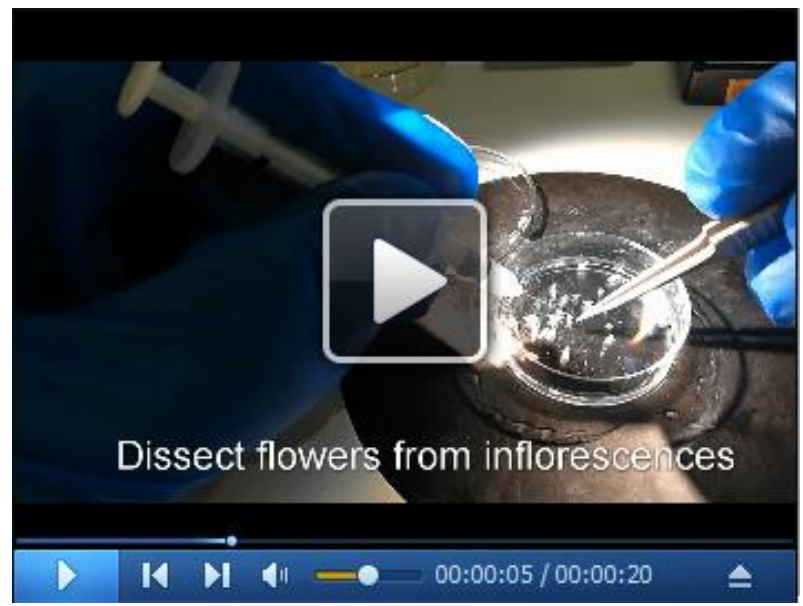

Video 1. Dissect flowers from inflorescences

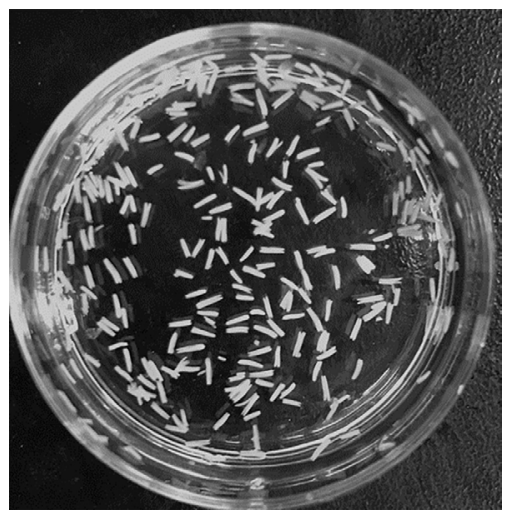

Figure 2. Maize anthers fixed in $4 \%$ paraformaldehyde

3. Fix anthers for $30 \mathrm{~min}$ in a small Petri dish on a rocking platform shaker at low speed at room temperature. Anthers should be swirling slightly and float on the surface.

4. Pipette out the fixative and wash anthers for $30 \mathrm{~min}$ in $4 \mathrm{ml}$ of $1 \times$ Buffer $\mathrm{A}$ on a rocking platform shaker at room temperature.

5. Pipette out buffer $A$ and pipette in fresh $1 x$ Buffer $A$ to the Petri. Seal the Petri dish with parafilm. Anthers can be stored at $4{ }^{\circ} \mathrm{C}$ for several months.

B. Embedding maize meiocytes in polyacrylamide pads

1. Mix equal amounts of $2 x$ Buffer $A$ and acrylamide/bisacrylamide solution (500 $\mu \mathrm{l}$ of $2 x$ Buffer $A$ $+500 \mu \mathrm{l}$ of acrylamide/bisacrylamide solution per 6 slides). Vortex briefly.

2. Aliquot into microfuge tubes, $100 \mu \mathrm{l}$ per tube. Prepare one microfuge tube for each slide.

3. Place 5 to 10 anthers previously fixed in $4 \%$ formaldehyde in a drop of $1 \times$ Buffer $A$ (about $60 \mu \mathrm{l}$ ) on a piece of parafilm (Figure 3). 


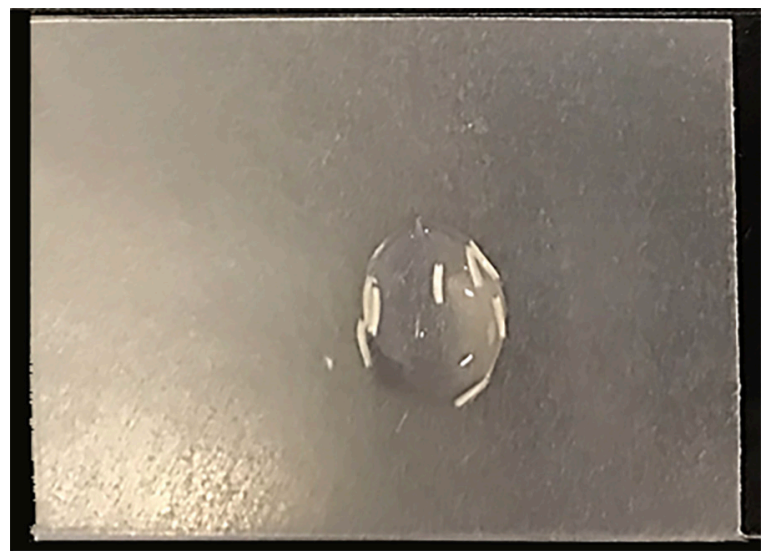

Figure 3. Slide with anthers in buffer A on a piece of parafilm

4. Release meiocytes from anthers under a dissecting microscope. To do it, pick an anther, hold it with forceps at one end, and cut off the other end with a sharp scalpel.

5. Squeeze meiocytes from the anther into another drop of 1x Buffer A using the blunt end of the scalpel.

6. Proceed to the next anther. Use 5 anthers per slide.

7. After finishing the last anther, swirl the drop containing meiocytes (Figure 4).

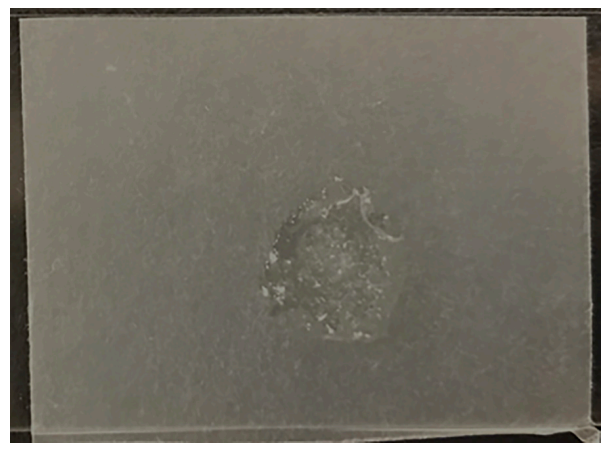

Figure 4. Slides with dissected anthers on a piece of parafilm

8. Pipette $10 \mu \mathrm{l}$ of the meiocyte suspension onto a center of a glass microscope coverslip using a cut pipet tip (Figure 5).

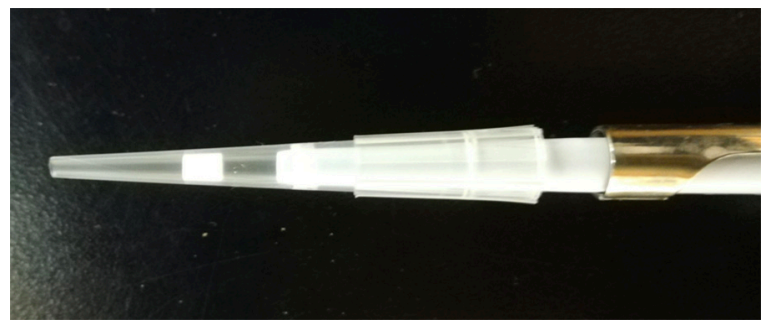

Figure 5. A cut pipette tip 
9. To a microfuge tube with the Buffer A/acrylamide solution, add $5 \mu \mathrm{l}$ of $20 \%$ sodium sulfite and $5 \mu \mathrm{l}$ of $20 \%$ ammonium persulfate. Vortex briefly. Take $5 \mu \mathrm{l}$ of the solution and add to the drop of meiocyte suspension. Swirl several times with a pipette tip. Act quickly as the acrylamide will start polymerizing.

10. Place another coverslip on the top of the meiocyte suspension drop. Place it at a $45^{\circ}$ angle relative to the bottom coverslip (Figure 6).

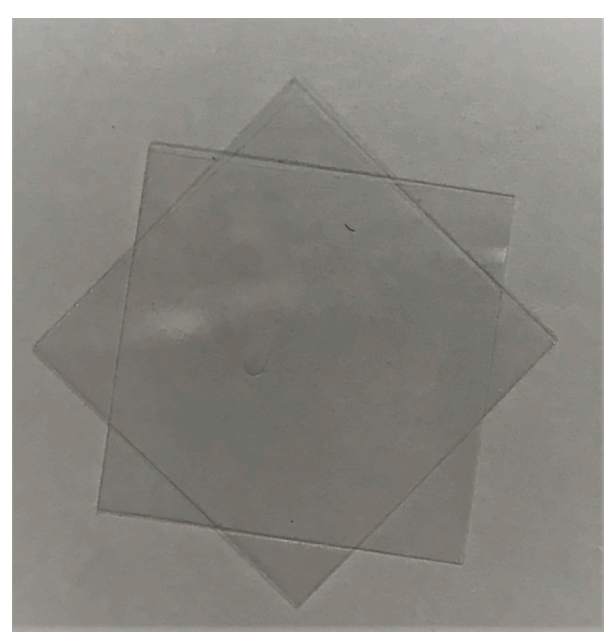

Figure 6. Polymerizing meiocyte-containing acrylamide between two coverslips

11. Leave for $1 \mathrm{~h}$ at room temperature to polymerize.

12. Separate the coverslips using a razor blade (Figure 7).

Note: Open the polyacrylamide pad slowly. The pad should mostly stick to one coverslip. Move to the next step immediately and do not let the acrylamide pad dry out.

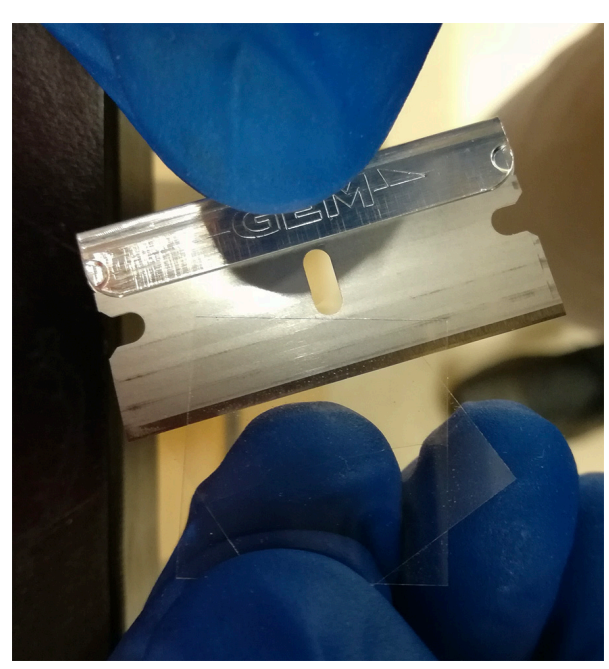

Figure 7. Opening the coverslip with a razor 
C. Immunolabeling

1. Place polyacrylamide pad with embedded meiocytes, polyacrylamide side up, in a six-well tissue culture plate.

2. Wash the pad twice with $1 \mathrm{ml}$ of $1 \times$ PBS buffer, $10 \mathrm{~min}$ for each wash.

Note: Avoid pipetting directly onto the polyacrylamide pad. When removing solutions, vacuum pump can also be used to remove liquid quickly.

3. Permeabilize the cells for $1 \mathrm{~h}$ in $1 \mathrm{ml}$ of Permeabilization buffer.

4. Block for $2 \mathrm{~h}$ in $1 \mathrm{ml}$ of blocking buffer.

5. Remove the blocking buffer by pipetting and apply primary antibodies, diluted 1:50 to 1:200, depending on the antibodies, in $50 \mu \mathrm{l}$ of blocking buffer onto the center of the pad.

6. Place the six-well plate on a layer of several wet paper towels in a tupperware box. Close the lid tightly. This step is especially important during winter when the air inside is very dry, as the pad would otherwise dry out quickly. Incubate overnight (12-14 h) at room temperature.

7. On the second day, wash the pads in $1 \mathrm{ml}$ of washing buffer eight times without shaking, $1 \mathrm{~h}$ for each wash in room temperature.

8. At the end of the day, add $1 \mathrm{ml}$ of washing buffer and leave overnight at room temperature.

9. On the third day, wash the pads in $1 \mathrm{ml}$ washing buffer for 4 to 6 times, $1 \mathrm{~h}$ for each wash. Note: The multiple washing steps over two days facilitate better removal of primary antibody and lower slide background during imaging. However, to speed up the process, washing can be shortened to 4 times, 30 min each wash. Then, move immediately to adding secondary antibody (Step C10). The same modification can be applied to days 4 and 5 (Steps C11 and C13) washes.

10. Remove the washing buffer and apply secondary antibodies diluted 1:200 in $50 \mu$ of blocking buffer. Incubate overnight in a humid chamber as described in Step C6.

Note: It is recommended that the 6-well plate be kept in darkness after the secondary antibody addition to protect fluorophores from photobleaching.

11. On the fourth day, wash the pads in $1 \mathrm{ml}$ of washing buffer for eight times, $1 \mathrm{~h}$ for each wash.

12. At the end of the day, add $1 \mathrm{ml}$ of Washing buffer and leave overnight at room temperature.

13. On the fifth day, wash the pads twice in $1 \mathrm{ml}$ of $1 x \mathrm{PBS}, 10 \mathrm{~min}$ for each wash.

14. Stain in $500 \mu \mathrm{l}$ of $10 \mu \mathrm{g} / \mathrm{ml}$ DAPI solution for $30 \mathrm{~min}$ at room temperature.

15. Wash three times, $10 \mathrm{~min}$ for each wash in $1 \mathrm{ml}$ of $1 \mathrm{x}$ PBS.

16. Remove all wash solution by pipetting. Incubate three times in DABCO antifade solution. Each time, put one or two drops of the DABCO antifade onto the slide, leave for one minute and remove excess solution

Note: When removing excess $D A B C O$, proceed carefully to avoid damaging the pad.

17. Take out the coverslip from the six-well plate and remove excess DABCO. Place the coverslip, the polyacrylamide side up, in a center of a glass microscope slide.

Note: Add a drop of water on the glass slide, underneath the coverslip. It will help immobilize the coverslip on the slide.

18. Put a clean coverslip on the top of the pad. Carefully remove all excess DABCO. 
Note: It is important to remove the excess DAPCO, as it may make the slide too thick, interfering with imaging.

19. Seal the slides with nail polish, and store at $-20^{\circ} \mathrm{C}$. Prior to imaging, take out the slides and keep in room temperature for $30 \mathrm{~min}$. Examine the slides under a fluorescent microscope.

Note: This protocol was successfully tested using antibodies against the anti-ASY1 and antiZYP1 (Ronceret et al., 2009) antibodies.

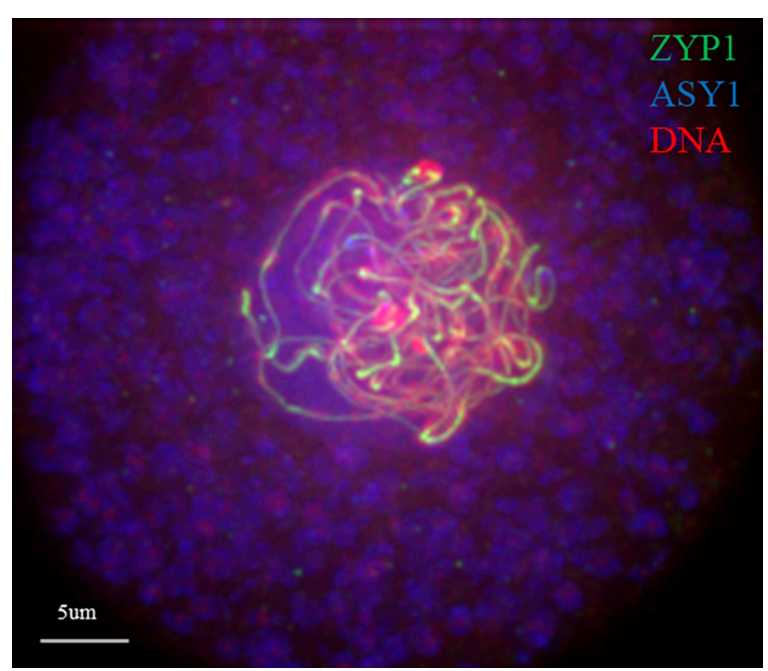

Figure 8. Maize meiocyte at the pachytene stage immunolabelled with the anti-ZYP1 (green) and anti-ASY1 (blue) antibodies. Chromatin (red) was stained with DAPI.

\section{Recipes}

1. $1 \times$ Buffer $A$

Mix $50 \mathrm{ml}$ of Buffer $A$ and $50 \mathrm{ml}$ of autoclaved water

Note: Make fresh buffer every time.

2. $2 x$ Buffer $A$

$2 \mathrm{ml}$ of $10 \mathrm{x}$ buffer $A$ salts

$10 \mu \mathrm{l}$ Spermine stock

$25 \mu$ l Spermidine stock

$20 \mu$ DTT stock

$3.2 \mathrm{ml}$ sorbitol

Add water up to $10 \mathrm{ml}$, filter-sterilize and store at $4{ }^{\circ} \mathrm{C}$

3. 10x Buffer $A$ salts

150 mM PIPES

$800 \mathrm{mM} \mathrm{KCl}$

$200 \mathrm{mM} \mathrm{NaCl}$

20 mM EDTA

5 mM EGTA 
Bring to $90 \%$ of final volume, adjust $\mathrm{pH}$ with $1 \mathrm{M} \mathrm{NaOH}$ to 6.8 . Bring to $100 \%$ final volume. Store at $4{ }^{\circ} \mathrm{C}$

4. Spermine stock

$0.4 \mathrm{M}$ spermine tetra $\mathrm{HCl}$ in $50 \mathrm{mM}$ PIPES $\mathrm{pH} 7.0$

Store at $-20^{\circ} \mathrm{C}$

5. Spermidine stock

$0.4 \mathrm{M}$ Spermidine in $50 \mathrm{mM}$ PIPES $\mathrm{pH} 7.0$

Store at $-20^{\circ} \mathrm{C}$

6. DTT stock

$1.0 \mathrm{M}$ dithiothreotol in $0.01 \mathrm{M}$ sodium acetate $\mathrm{pH} 5.2$

Store at $-20^{\circ} \mathrm{C}$

7. Sorbitol solution

$2 \mathrm{M}$ solution in water

Store at $4{ }^{\circ} \mathrm{C}$

8. $20 \%(w / v)$ Sodium sulfite

Dissolve $0.1 \mathrm{~g}$ in $0.5 \mathrm{ml} \mathrm{H}_{2} \mathrm{O}$

Store at $-20^{\circ} \mathrm{C}$

9. $20 \%(w / v)$ Ammonium persulfate

Dissolve $0.1 \mathrm{~g}$ in $0.5 \mathrm{ml} \mathrm{H}_{2} \mathrm{O}$

Store at $-20{ }^{\circ} \mathrm{C}$

10. 10x PBS (Phosphate Buffered Saline)

$80 \mathrm{~g}$ of $\mathrm{NaCl}$

$2.0 \mathrm{~g}$ of $\mathrm{KCl}$

$14.4 \mathrm{~g}$ of $\mathrm{Na}_{2} \mathrm{HPO}_{4}$

$2.4 \mathrm{~g}$ of $\mathrm{KH}_{2} \mathrm{PO}_{4}$

a. Dissolve the salts in $800 \mathrm{ml}$ distilled $\mathrm{H}_{2} \mathrm{O}$

b. Adjust $\mathrm{pH}$ to 7.4

c. Adjust volume to $1 \mathrm{~L}$ with additional distilled $\mathrm{H}_{2} \mathrm{O}$

d. Sterilize by autoclaving

11. Permeabilization buffer

$1 \times$ PBS

$1 \%$ Triton $\mathrm{X}-100$

1 mM EDTA

12. Blocking buffer

1x PBS

$3 \%$ BSA

1 mM EDTA

$0.1 \%$ Tween 20

Note: Make fresh blocking buffer for every use. 
13. Washing buffer

$1 \times$ PBS

$0.1 \%$ Tween 20

1 mM EDTA

14. DABCO antifade solution

$2.5 \%$ w/v DABCO (1,4 diazabicyclo-[2,2,2] octane)

$50 \mathrm{mM}$ Tris $\mathrm{pH} 8.0$

$90 \%$ glycerol

Combine components, dissolve DABCO by warming to $70{ }^{\circ} \mathrm{C}$, mix. Aliquot and store at $-20{ }^{\circ} \mathrm{C}$

The solution is very viscous

15. DAPI solution

Dissolve $1 \mu \mathrm{g} / \mathrm{ml}$ of DAPI powder in water

16. Carnoy's fixative

$10 \mathrm{ml}$ Acetic acid

$30 \mathrm{ml}$ Ethanol

Mix well before use

\section{Acknowledgments}

We thank Mateusz Zelkowski for pictures and video. Research to improve this protocol was supported by a grant from the National Science Foundation (IOS-1848788). This protocol is an adaptation of procedures of Franklin et al. (1999) and Ronceret et al. (2009). Authors declare no competing interests.

\section{$\underline{\text { References }}$}

1. Dukowic-Schulze, S., Sundararajan, A., Ramaraj, T., Mudge, J. and Chen, C. (2014). Sequencing-based large-scale genomics approaches with small numbers of isolated maize meiocytes. Front Plant Sci 5: 57.

2. Franklin, A. E., McElver, J., Sunjevaric, I., Rothstein, R., Bowen, B. and Cande, W. Z. (1999). Three-dimensional microscopy of the Rad51 recombination protein during meiotic prophase. Plant Cell 11(5): 809-824.

3. Ronceret, A., Doutriaux, M. P., Golubovskaya, I. N. and Pawlowski, W. P. (2009). PHS1 regulates meiotic recombination and homologous chromosome pairing by controlling the transport of RAD50 to the nucleus. Proc Natl Acad Sci U S A 106(47): 20121-20126. 